\title{
BMJ Open Clinical characteristics of hospitalised patients with COVID-19 and the impact on mortality: a single-network, retrospective cohort study from Pennsylvania state
}

To cite: Gadhiya KP, Hansrivijit P, Gangireddy M, et al. Clinical characteristics of hospitalised patients with COVID-19 and the impact on mortality: a single-network, retrospective cohort study from Pennsylvania state. BMJ Open 2021;11:e042549. doi:10.1136/ bmjopen-2020-042549

- Prepublication history and additional supplemental material for this paper are available online. To view these files, please visit the journal online (http://dx.doi.org/10.1136/ bmjopen-2020-042549).

$\mathrm{KPG}, \mathrm{PH}$ and $\mathrm{MG}$ contributed equally.

Received 08 July 2020 Revised 07 October 2020 Accepted 18 March 2021
Check for updates

(c) Author(s) (or their employer(s)) 2021. Re-use permitted under CC BY-NC. No commercial re-use. See rights and permissions. Published by BMJ.

${ }^{1}$ Department of Internal Medicine, UPMC Pinnacle, Harrisburg, Pennsylvania, USA ${ }^{2}$ Department of Infectious Diseases, UPMC Pinnacle, Harrisburg, Pennsylvania, USA

Correspondence to Dr Panupong Hansrivijit; hansrivijitp@upmc.edu

\section{ABSTRACT}

Objective COVID-19 is a respiratory disease caused by SARS-CoV-2 with the highest burden in the USA. Data on clinical characteristics of patients with COVID-19 in US population are limited. Thus, we aim to determine the clinical characteristics and risk factors for in-hospital mortality from COVID-19.

Design Retrospective observational study.

Setting Single-network hospitals in Pennsylvania state.

Participants Patients with confirmed SARS-CoV-2

infection who were hospitalised from 1 March to 31 May 2020.

Primary and secondary outcome measures Primary outcome was in-hospital mortality. Secondary outcomes were complications, such as acute kidney injury (AKI) and acute respiratory distress syndrome (ARDS).

Results of 283 patients, $19.4 \%$ were non-survivors. The mean age of all patients was $64.1 \pm 15.9$ years. $56.2 \%$ were male and $50.2 \%$ were white. Several factors were identified from our adjusted multivariate analyses to be associated with in-hospital mortality: increasing age (per 1-year increment; OR 1.07 (1.045 to 1.105)), hypoxia (oxygen saturation <95\%; OR 4.630 (1.934 to 1.111)), opacity/infiltrate on imaging (OR 3.077 (1.276

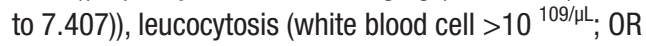
2.732 (1.412 to 5.263$)$ ), ferritin $>336 \mathrm{ng} / \mathrm{mL}$ (OR 4.016 (1.195 to 13.514)), lactate dehydrogenase $>200 \mathrm{U} / \mathrm{L}$ (OR 7.752 (1.639 to 37.037$)$ ), procalcitonin $>0.25 \mathrm{ng} /$ $\mathrm{mL}$ (OR 2.404 (1.011 to 5.714)), troponin I >0.03 ng/ $\mathrm{mL}$ (OR 2.242 (1.080 to 4.673)), need for advanced oxygen support other than simple nasal cannula (OR 4.608-13.889 (2.053 to 31.250)), intensive care unit admission/transfer (OR 13.699 (6.135 to 30.303)), renal replacement therapy (OR 21.277 (5.025 to 90.909)), need for vasopressor (OR 22.222 (9.434 to 52.632)), ARDS (OR 23.810 (10.204 to 55.556)), respiratory acidosis (OR 7.042 (2.915 to 16.949)), and AKI (OR 3.571 (1.715 to 7.407)). When critically ill patients were analysed independently, increasing Sequential Organ Failure Assessment score (OR 1.544 (1.168 to 2.039)), AKI (OR 2.128 (1.111 to 6.667)) and ARDS (OR 6.410 (2.237 to 18.182)) were predictive of in-hospital mortality.
Strengths and limitations of this study

- Individual patient's chart was reviewed.

- Multivariate analysis (binary logistic regression model) was used to report the results.

- Retrospective, observational design.

- Limited sample size.

- Only hospitalised patients were included in the studies.

Conclusion We reported the characteristics of ethnically diverse, hospitalised patients with COVID-19 from Pennsylvania state.

\section{INTRODUCTION}

COVID-19 is a respiratory disease caused by SARS-CoV-2 which has become a pandemic in early 2020. The spread of this virus was originally started in Wuhan, China in December 2019 and rapidly escalated to 216 countries within 5 months with the highest number of infected cases in the USA. ${ }^{1}$ As of 29 August 2020, the reported cumulated number of confirmed cases in the USA was close to 6 million with a mortality rate of $3.09 \% .^{1}$

As of 29 August 2020, the Pennsylvania Department of Health has announced more than 129056 confirmed cases of COVID-19 leading to 7671 deaths, making Pennsylvania the 13th state with the highest confirmed cases. $^{2}$ To date, the characteristics of infected patients in the USA were reported in the states of Washington $(n=21)$, California $(n=1299)$ and New York $(n=5700)$ in chronological order. ${ }^{3-5}$ The mortality across the US studies ranged from $6.3 \%$ to $24 \%$, depending on the severity of COVID-19. Although the characteristics of hospitalised patients with COVID-19 have been reported in other states, 
there are some limitations that preclude the generalisation of the results toward our patient population. Studies from Washington and California were conducted and published during an early stage of the pandemic where treatment options, such as remdesivir or dexamethasone, were not recommended as the standard of care. In addition, multivariate analysis was not performed in the New York City cohort. The associations between clinical characteristics and in-hospital mortality in the US population have not been clearly established.

Guan $e t a t^{6}$ first described the clinical characteristics of 1099 patients infected with SARS-CoV-2 across China. In this study, the overall mortality was $1.4 \%$. However, the association between clinical risk factors and mortality was not described. Later, Du et al and Zhou et al demonstrated that older age, higher Sequential Organ Failure Assessment (SOFA) score, D-dimer $>1 \mu \mathrm{g} / \mathrm{mL}$, cardiac troponin $\mathrm{I} \geq 0.05 \mathrm{ng} / \mathrm{mL}$, and pre-existing concurrent cardiovascular and cerebrovascular diseases were significant predictors for increased mortality from COVID-19. ${ }^{78}$ However, these findings were primarily based on Chinese population; thus, it has been unconfirmed if the results can be applicable to other patient populations.

Clinical management of COVID-19 has been dynamic and variable based on available research, which has largely been in vitro, such as a combination of hydroxychloroquine and azithromycin, ${ }^{9}$ ascorbic acid, ${ }^{10}$ ivermectin ${ }^{11}$ and zinc. ${ }^{12}$ These therapies have not been proven beneficial in clinical studies. In the current study, we provide our experience on treatment options for patients infected with SARS-CoV-2.

In this retrospective cohort, we aimed to demonstrate the clinical characteristics of patients with COVID19 , treatment outcomes and the impact on in-hospital mortality in an ethnically diverse population.

\section{MATERIALS AND METHODS \\ Study design}

This is a retrospective cohort study from seven hospitals under UPMC Pinnacle network located across the state of Pennsylvania. Written informed consent was waived due to the retrospective, observational nature of the study. Our current study followed the Declaration of Helsinki.

\section{Patient and public involvement}

No patient involvement.

\section{Data source and patient population}

Data were collected by extracting electronic medical records from 1 March to 31 May 2020 through UPMC Pinnacle COVID-19 registry. Adult patients aged $\geq 18$ years who were hospitalised with confirmed SARS-CoV-2 infection by real-time PCR (RT-PCR) from nasopharyngeal swab were included in this study. We excluded nonhospitalised patients, patients $<18$ years of age, presumed SARS-CoV-2 infection, pregnant women, out-of-system transfer and patients enrolled in clinical trials. Transfer within the system was considered one admission. For patients with multiple admissions with study period, the first admission for COVID-19 was reviewed.

\section{Data collection}

Individual patient charts were reviewed by three independent authors to prevent observer bias. Collected data were divided into: demographics, comorbidities, signs and symptoms, laboratory findings, radiographic findings, treatments/interventions, complications and outcomes. Online supplemental document 1 summarises the description of each variable in our cohort as well as the cut-off values for each variable.

The SOFA score ${ }^{13}$ was calculated on the first day of intensive care unit (ICU) admission. Estimated glomerular filtration rate (eGFR) was calculated using Chronic Kidney Disease (CKD)-Epidemiology Collaboration equation. ${ }^{14}$ Acute kidney injury (AKI) was defined by an increase in serum creatinine by $0.3 \mathrm{mg} / \mathrm{dL}(27 \mu \mathrm{mol} / \mathrm{L})$ or $\geq 1.5$ times from the baseline value within 48 hours. ${ }^{15}$ CKD was defined by the Kidney Diseases Improving Global Outcomes guidelines. ${ }^{16}$ Patients with a history of end-stage kidney disease on dialysis prior to admission were not counted toward 'requirement of renal replacement therapy (RRT)/haemodialysis' during the hospital stay. Acute respiratory distress syndrome (ARDS) was defined by the Berlin criteria. ${ }^{17}$ Arrhythmias as complications were defined either tachycardia or bradycardia that were new onset, occurred during hospitalisation with COVID-19. In this study, prolongation of QT segment was defined as the QT duration $>500 \mathrm{~ms}$.

\section{Study outcomes}

The primary outcome was in-hospital mortality. The secondary outcome included treatment outcomes and complications such as recovery/discharge, AKI, ARDS, arrhythmias, QT prolongation, venous thromboembolism, arterial thrombosis, cerebrovascular events, heart failure and myocardial infarction.

\section{Statistical analysis}

All analyses were conducted using SPSS software V.23.0 (IBM Corp). Descriptive analyses were reported in percentage for categorical data and in mean \pm SD or median (IQR) depending on the data distribution. Comparisons of outcomes for each variable were evaluated using Pearson's $\chi^{2}$ tests or Fisher's exact tests (for categorical data) and two-sample independent t-test (for continuous data). Fisher's exact tests were opted if the total sample in any cell count was less than five. A p value less than 0.05 is considered statistically significant. Missing data were not included in the analysis.

\section{Logistic regression analysis}

Clinical risk factors that were significant from standard analyses (Pearson's $\chi^{2}$ tests, Fisher's exact tests, t-tests) were included in univariate binary logistic regression analysis. ORs were reported along with 95\% CI. A 95\% CI that crosses 1.0 and a $\mathrm{p}$ value of less than 0.05 are considered 
statistically significant. ${ }^{18}$ Variables that remained statistically significant on univariate analysis were included in multivariate analysis using logistic regression method to adjust for other covariates. For the analyses of overall mortality predictors, each variable was analysed by only one model that was adjusted for several potential confounding factors for that particular variable. Model 1 was adjusted for age, sex, ethnicity and obesity. Model 2 was adjusted for age, sex, ethnicity, obesity and need for oxygen therapy. Model 3 is adjusted for age, sex, ethnicity, obesity, asthma/chronic obstructive pulmonary disease (COPD), the need for oxygen therapy and ICU admission. Model 4 is adjusted for age, sex, ethnicity, obesity, $\mathrm{CKD}$, the need for oxygen therapy and ICU admission. Model 5 is adjusted for age, sex, ethnicity, obesity, coronary artery disease, heart failure, history of arrhythmia/ conduction disorder and ICU admission. The rationale for each model adjustment in multivariate analysis is available in online supplemental document 2.

\section{Survival analysis}

Kaplan-Meier analysis was used to present the survival by plotting between cumulative survival against hospital stay in all included patients and in patients requiring ICU.

\section{RESULTS}

\section{Baseline characteristics and patient outcomes}

A total of 12938 patients were identified during the study period. Thirty-nine patients were outpatient and did not require hospitalisation. After excluding patients with negative PCR $(\mathrm{n}=7374)$, duplicate medical records $(n=145)$, pregnant woman $(n=3)$ and clinical trial patients $(n=2), 283$ patients were included for further analysis. The flow chart of data selection from the UPMC Pinnacle COVID-19 registry is depicted in figure 1. Table 1 summarises the demographics and baseline characteristics of included patients. All patients had confirmed SARS-CoV-2 infection by RT-PCR. Of 283 patients, $80.6 \%$ were survivors and $19.4 \%$ were non-survivors. The mean age of all patients was $64.1 \pm 15.9$ years. A total of $56.2 \%$ were male and $50.2 \%$ were Caucasian. Non-survivors were significantly older and had higher proportion of hypertension, CKD and had lower mean eGFR. Moreover, hypoxia on presentation, rales/crackles on physical examination, leucocytosis, lymphocytopenia, respiratory acidosis, transaminitis and opacity/infiltrate on imaging were common presentations in non-survivors. Higher inflammatory markers, such as D-dimer, ferritin, lactate dehydrogenase $(\mathrm{LDH}), \mathrm{C}$ reactive protein and procalcitonin were significantly prevalent in deceased patients. The need for oxygen therapy regardless of the mode of oxygen delivery was higher among those who did not survive. Furthermore, non-survivors were more likely to have received ICU admission/transfer, extracorporeal membrane oxygenation (ECMO), RRT, use of vasopressors, use of antibiotics, azithromycin, hydroxychloroquine, steroids, ascorbic acid, zinc, tocilizumab and convalescent plasma.

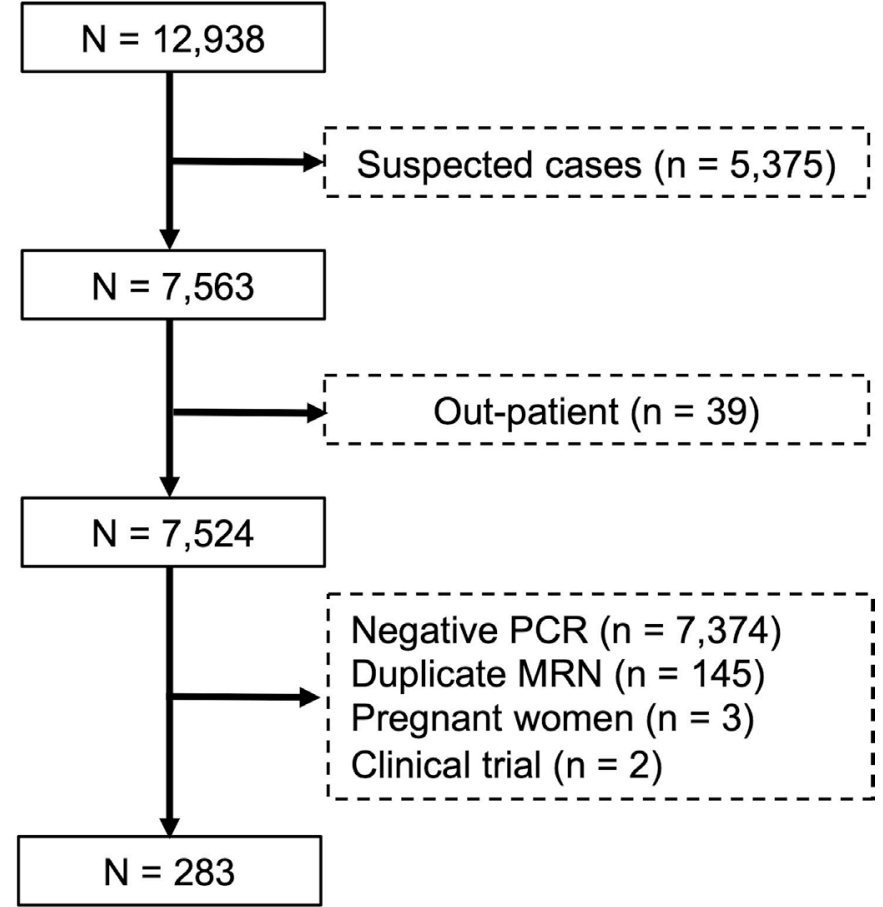

Figure 1 Flow chart of subject selection from UPMC Pinnacle COVID-19 registry from 1 March to 31 May 2020. $\mathrm{MRN}$, medical record number.

Of overall complications, the prevalence of AKI, ARDS, arrhythmias and superimposed bacteraemia was significantly higher in non-survivors. There was no significant difference in mean hospital stay between survivors and non-survivors. Up to $78.8 \%$ recovered or were discharged from the hospital. Only two patients remained hospitalised as of 18 June 2020. The mean hospital stay was similar between patients who received remdesivir versus those who did not $(9.0 \pm 4.7$ and $7.6 \pm 7.8$ days, respectively; $\mathrm{p}=0.359$ ). In contrast, patients who received tocilizumab had significantly longer hospital stay compared with those who did not receive tocilizumab $(15.3 \pm 11.7$ and $7.4 \pm 7.2$ days, respectively; $\mathrm{p}<0.001$ ).

\section{Univariate analysis}

All factors except superimposed bacteraemia remained significant on univariate analysis. The OR of each clinical predictor for overall in-hospital mortality is depicted in table 2. Logistic regression analysis cannot be performed on the following variables: D-dimer $(>500 \mathrm{ng} / \mathrm{mL}), \mathrm{C}$ reactive protein $(>1 \mathrm{mg} / \mathrm{dL})$ and the need for ECMO as at least one cell count was zero. Moreover, in a univariate analysis, we found that hydroxychloroquine treatment was associated with increased risk of QT prolongation (OR 3.401; 95\% CI 1.473 to 7.874; $\mathrm{p}=0.002$ ).

\section{Multivariate analysis}

Variables that were significant on univariate analysis were included in multivariate logistic regression analysis (table 3). In model 1 (adjusted for age, sex, ethnicity and obesity), increasing patient age, hypoxia, opacity/ infiltrate on imaging, leucocytosis, ferritin $>336 \mathrm{ng} / \mathrm{mL}$, 
Table 1 Demographics and baseline characteristics of included patients

\begin{tabular}{|c|c|c|c|c|}
\hline Characteristics & $\begin{array}{l}\text { All patients } \\
(n=283)\end{array}$ & $\begin{array}{l}\text { Survivors } \\
(n=228)\end{array}$ & $\begin{array}{l}\text { Non-survivors } \\
(n=55)\end{array}$ & $P$ value \\
\hline Male & $159(56.2)$ & $125(54.8)$ & $34(61.8)$ & 0.348 \\
\hline Age (year) & $64.1(15.9)^{*}$ & $61.9(15.8)^{\star}$ & $72.8(13.5)^{\star}$ & $<0.001 \dagger$ \\
\hline \multicolumn{5}{|l|}{ Ethnicity } \\
\hline Caucasian & $143(50.5)$ & $111(48.7)$ & $32(58.2)$ & \\
\hline African-American & $88(31.1)$ & $73(32.0)$ & $15(27.3)$ & \\
\hline Hispanic/Latino & $32(11.3)$ & $27(11.8)$ & $5(9.1)$ & 0.705 \\
\hline Asian & $17(6.0)$ & $14(6.1)$ & $3(5.5)$ & \\
\hline Others & $3(1.1)$ & $3(1.3)$ & $0(0)$ & \\
\hline \multicolumn{5}{|l|}{ Comorbidities } \\
\hline Obesity (BMI $\geq 30$ kg/m²) & $132(46.6)$ & $102(44.7)$ & $30(54.5)$ & 0.191 \\
\hline Current/former smokers & $109(38.5)$ & $88(38.6)$ & $21(38.2)$ & 0.955 \\
\hline Hypertension & $189(66.8)$ & $145(63.6)$ & $44(80.0)$ & $0.020 \dagger$ \\
\hline Diabetes mellitus & $108(38.2)$ & $81(35.5)$ & $27(49.1)$ & 0.063 \\
\hline Hyperlipidaemia & $121(42.8)$ & $94(41.2)$ & $27(49.1)$ & 0.290 \\
\hline Coronary artery disease & $50(17.7)$ & $40(17.5)$ & $10(18.2)$ & 0.911 \\
\hline Heart failure/cardiomyopathy & $53(18.7)$ & $40(17.5)$ & $13(23.6)$ & 0.299 \\
\hline Arrhythmia/conduction disorders & $45(15.9)$ & $36(15.8)$ & $9(16.4)$ & 0.917 \\
\hline Chronic kidney disease & $66(23.3)$ & $46(20.2)$ & $20(36.4)$ & $0.011 \dagger$ \\
\hline End-stage kidney disease & $13(4.6)$ & $12(5.3)$ & $1(1.8)$ & 0.474 \\
\hline Asthma/COPD & $73(25.8)$ & $54(23.7)$ & $19(34.5)$ & 0.098 \\
\hline Cerebrovascular disease & $40(14.1)$ & $32(14.0)$ & $8(14.5)$ & 0.922 \\
\hline \multicolumn{5}{|l|}{ Signs and symptoms } \\
\hline Cough & $185(65.4)$ & $149(65.4)$ & $36(65.5)$ & 0.988 \\
\hline Dyspnoea & $203(71.7)$ & $158(69.3)$ & $45(81.8)$ & 0.064 \\
\hline Hypoxia $\left(\mathrm{SpO}_{2}<95 \%\right)$ & $178(62.9)$ & $130(57.0)$ & $48(87.3)$ & $<0.001 \dagger$ \\
\hline Rhinorrhoea & $29(10.2)$ & $26(11.4)$ & $3(5.5)$ & 0.226 \\
\hline Fever/chills & $179(63.3)$ & $143(62.7)$ & $36(65.5)$ & 0.706 \\
\hline Chest pain & $35(12.4)$ & $32(14.0)$ & $3(5.5)$ & 0.109 \\
\hline Headache & $28(9.9)$ & $26(11.4)$ & $2(3.6)$ & 0.128 \\
\hline Gastrointestinal symptoms & $79(27.9)$ & $68(29.8)$ & $11(20.0)$ & 0.145 \\
\hline Asymptomatic & $8(2.8)$ & $8(3.5)$ & $0(0)$ & 0.361 \\
\hline Rales/crackles & $57(20.1)$ & $40(17.5)$ & $17(30.9)$ & $0.027 \dagger$ \\
\hline Rhonchi & $57(20.1)$ & $45(19.7)$ & $12(21.8)$ & 0.730 \\
\hline Reduced breath sound & $63(22.3)$ & $48(21.1)$ & $15(27.3)$ & 0.320 \\
\hline \multicolumn{5}{|l|}{ Laboratory findings } \\
\hline 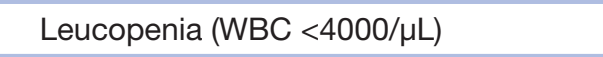 & $56(19.8)$ & $46(20.2)$ & $10(18.2)$ & 0.739 \\
\hline Leucocytosis (WBC >10 000/uL) & $80(28.3)$ & $53(23.2)$ & $27(49.1)$ & $<0.001 \dagger$ \\
\hline 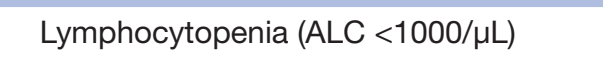 & $109(38.7)$ & $78(34.2)$ & $31(57.4)$ & $0.002 \dagger$ \\
\hline 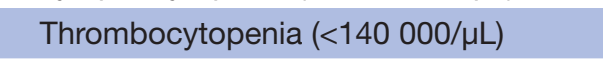 & $57(20.1)$ & $41(18.0)$ & $16(29.1)$ & 0.065 \\
\hline 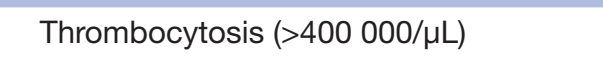 & $31(11.0)$ & $25(11.0)$ & $6(10.9)$ & 0.991 \\
\hline Respiratory acidosis & $43(21.3)$ & $18(11.8)$ & $25(50.0)$ & $<0.001 \dagger$ \\
\hline Transaminitis (ALT > $3 \times$ UNL) & $33(12.4)$ & $21(9.9)$ & $12(21.8)$ & $0.017 \dagger$ \\
\hline Serum creatinine $(\mathrm{mg} / \mathrm{dL})$ on admission & 1.06 (0.72)‡ & $1.59(1.88)^{*}$ & $1.64(1.15)^{\star}$ & 0.808 \\
\hline eGFR $\left(\mathrm{mL} / \mathrm{min} / 1.73 \mathrm{~m}^{2}\right)$ & $64.2(51.0)^{*}$ & $66.7(35.5)^{\star}$ & $53.6(25.3)^{\star}$ & $0.002 \dagger$ \\
\hline
\end{tabular}


Table 1 Continued

\section{Characteristics}

Troponin I (>0.03 ng/mL)

Inflammatory markers

D-dimer (>500 ng/mL)

Ferritin (>336 ng/mL)

Lactate dehydrogenase (>200 U/L)

$C$ reactive protein $(>1 \mathrm{mg} / \mathrm{dL})$

Procalcitonin (>0.25 ng/mL)

ST-T change on ECG

Radiographic findings

Opacity/infiltrate

Pleural effusion

Pulmonary congestion

Oxygen therapy/delivery

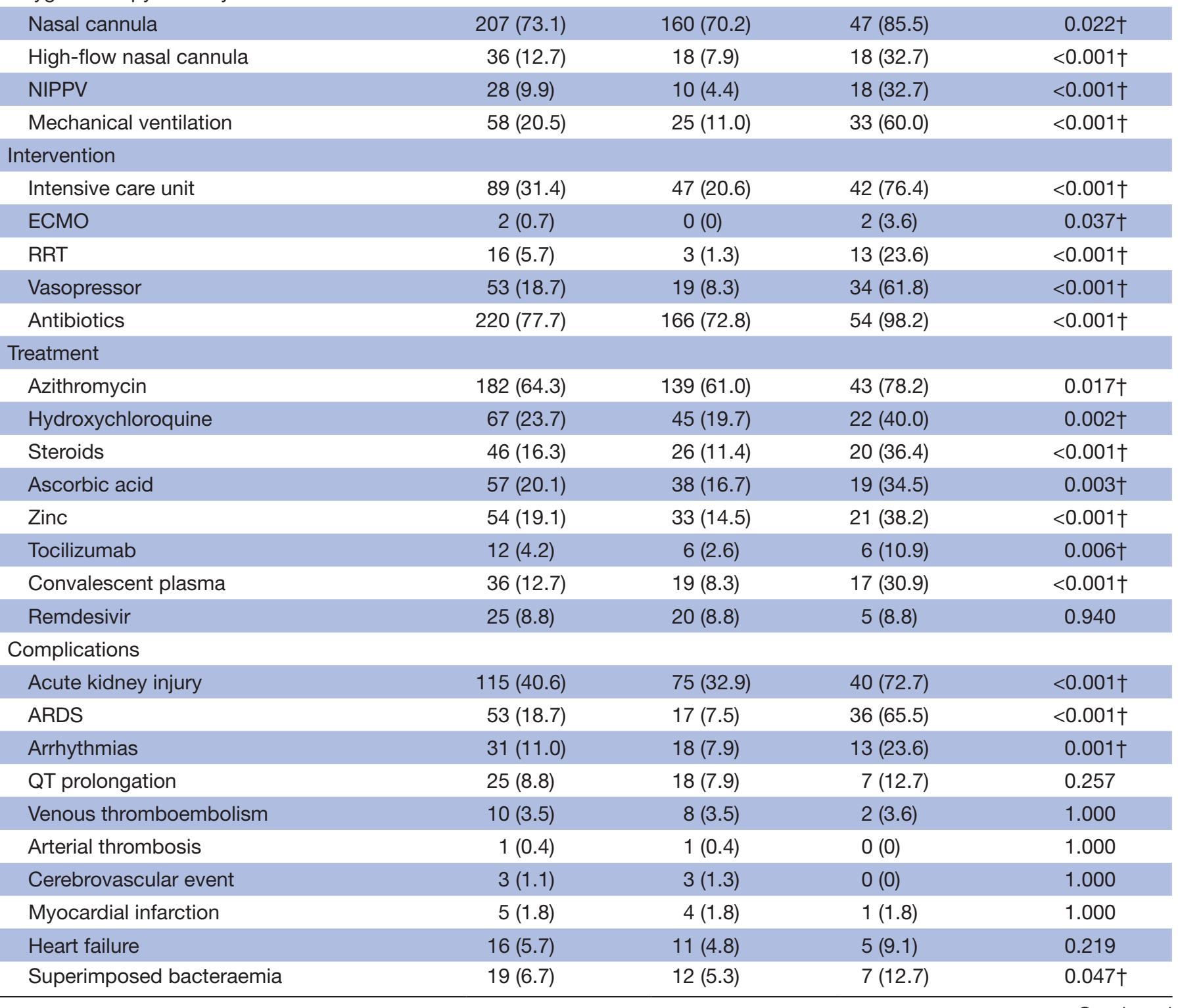

Continued

\begin{tabular}{ccll}
$\begin{array}{l}\text { All patients } \\
(\mathbf{n}=\mathbf{2 8 3})\end{array}$ & $\begin{array}{l}\text { Survivors } \\
(\mathbf{n}=\mathbf{2 2 8})\end{array}$ & $\begin{array}{l}\text { Non-survivors } \\
(\mathbf{n}=\mathbf{5 5})\end{array}$ & P value \\
\hline $91(39.1)$ & $61(33.0)$ & $30(62.5)$ & $<0.001 \dagger$
\end{tabular}

$\begin{array}{rrrr}135(80.4) & 101(75.4) & 34(100) & <0.001 \dagger \\ 109(65.3) & 78(59.1) & 31(88.6) & 0.001 \dagger \\ 108(73.0) & 77(67.0) & 31(93.9) & 0.002 \dagger \\ 152(87.4) & 115(83.9) & 37(100) & 0.005 \dagger \\ 73(47.1) & 50(41.7) & 23(65.7) & 0.012 \dagger \\ 84(31.8) & 63(29.7) & 21(40.4) & 0.139\end{array}$

$\begin{array}{ccrl}209(73.9) & 162(71.1) & 47(85.5) & 0.029 \dagger \\ 79(27.9) & 65(28.5) & 14(25.5) & 0.650 \\ 24(8.5) & 17(7.5) & 7(12.7) & 0.208 \\ 30(10.6) & 23(10.1) & 7(12.7) & 0.568\end{array}$


Table 1 Continued

\begin{tabular}{|c|c|c|c|c|}
\hline Characteristics & $\begin{array}{l}\text { All patients } \\
(n=283)\end{array}$ & $\begin{array}{l}\text { Survivors } \\
(\mathrm{n}=228)\end{array}$ & $\begin{array}{l}\text { Non-survivors } \\
(n=55)\end{array}$ & $P$ value \\
\hline Hospital stay (day) & $6.0(7.0) \ddagger$ & $7.4(7.53)^{\star}$ & $9.2(7.7)^{\star}$ & 0.125 \\
\hline Recovery/discharge & $223(78.8)$ & & & \\
\hline Remained hospitalised & $2(0.7)$ & & & \\
\hline
\end{tabular}

*Mean (SD).

†Statistically significant.

$\ddagger$ Median (IQR).

ALC, absolute lymphocyte count; ALT, alanine transaminase; ARDS, acute respiratory distress syndrome; BMI, body mass index; COPD, chronic obstructive pulmonary disease; ECMO, extracorporeal membrane oxygenation; eGFR, estimated glomerular filtration rate; NIPPV, non-invasive positive pressure ventilation; $\mathrm{RRT}$, renal replacement therapy; $\mathrm{SpO}_{2}$, oxygen saturation; UNL, upper normal limit; WBC, white blood cell.

$\mathrm{LDH}(>200 \mathrm{U} / \mathrm{L})$, procalcitonin $>0.25 \mathrm{ng} / \mathrm{mL}$, troponin I $>0.03 \mathrm{ng} / \mathrm{mL}$, use of high-flow oxygen nasal cannula, noninvasive positive pressure ventilation (NIPPV), mechanical ventilation, ICU admission/transfer, RRT, vasopressor, antibiotics and ARDS were independent risk factors for increased in-hospital mortality. In model 2 (adjusted for all variables in model 1 plus the need for oxygen therapy and ICU admission), hydroxychloroquine, ascorbic acid, zinc and convalescent plasma were not associated with increased mortality. In model 3 (adjusted for all variables in model 2 plus asthma/COPD), respiratory acidosis was associated with increased mortality. Moreover, AKI was an independent risk factor for in-hospital mortality from COVID-19 from model 4. In addition, we also found that hydroxychloroquine therapy was associated with QT prolongation (OR 2.874; $95 \%$ CI 1.189 to $6.944 ; \mathrm{p}=0.019$ ) after adjusted for covariates in model 2.

\section{Cohort of critically ill patients}

A total of 89 patients required intensive care during the study period. Of which, $47.2 \%$ died. The demographics and clinical characteristics of critically ill patients are demonstrated in table 4. Deceased ICU patients had significantly higher proportion of AKI and ARDS compared with survived ICU patients. The treatments were similar between survivors and non-survivor patients. In multivariate analysis, each 1-point increment of SOFA score was associated with increased death (OR 1.544; 95\% CI 1.168 to 2.039; $\mathrm{p}=0.002$ ) after adjusted for age, sex and ethnicity. Similarly, AKI (OR 2.128, 95\% CI 1.111 to $6.667 ; \mathrm{p}=0.034$ ) and ARDS (OR 6.410; 95\% CI 2.237 to 18.182; $\mathrm{p}=0.023$ ) are significantly predictive of in-hospital mortality among patients admitted to the ICU after adjusted for age, sex, ethnicity and SOFA score.

\section{Survival analysis}

Survival analyses evaluated using Kaplan-Meier curve of all patients were presented in figure 2A. The median survival time was 25.0 days with SE of 7.0. The KaplanMeier curves for ICU and no ICU patients were illustrated in figure $2 \mathrm{~B}$.

\section{DISCUSSION}

In this single-network, retrospective observation study, we found that the overall in-hospital mortality among hospitalised patients with COVID-19 was 19.4\%. The reported mortality among Chinese cohorts ranged from $11.7 \%$ to $28.2 \% .^{7819}$ However, our reported mortality rates appeared slightly lower than what previously described from New York City. Richardson et a $\tilde{e}$ found that the overall mortality of 5700 hospitalised patients with COVID-19 from 12 hospitals in New York City was $21 \%$. However, one could argue that our study has a significantly smaller sample size. Our data need confirmation from other studies with a larger sample size.

We identified several risk factors for mortality from COVID-19 using multivariate logistic regression analysis. Increasing age, hypoxia and opacity/infiltrate on imaging were associated with higher mortality. Moreover, we also found that patient survival diminished as the disease progressed, reflected by advancement in oxygen delivery (high-flow nasal cannula, NIPPV and mechanical ventilation). Requiring a simple oxygen nasal cannula did not affect mortality. Such findings are similar to previous literature. Older age is an independent risk factor for severe COVID-19 and mortality. ${ }^{720}$ In line with Zhou et al, increasing oxygen requirement and need for advanced oxygen delivery were predictive of death from COVID-19. ${ }^{8}$

Here, we showed that patients with COVID-19 requiring ICU had 13.7-fold increased risk of mortality. Critically ill patients generally had one or more organs in failure, and an increasing number of organ failure has been linked to elevated death in patients with sepsis. ${ }^{21}$ For patients with COVID-19, we demonstrated that kidney (AKI and RRT), pulmonary (respiratory acidosis and ARDS) and cardiovascular (vasopressor requirement) failure were 
Table 2 Clinical risk factors for overall in-hospital mortality using univariate binary logistic regression analysis

\begin{tabular}{|c|c|c|c|}
\hline Characteristics & OR & $95 \% \mathrm{Cl}$ & $P$ value \\
\hline Age (per 1-year increment) & 1.051 & 1.028 to 1.075 & $<0.001^{*}$ \\
\hline Hypertension & 2.288 & 1.121 to 4.673 & $0.024^{*}$ \\
\hline Chronic kidney disease & 2.262 & 1.195 to 4.274 & $0.012^{*}$ \\
\hline Hypoxia $\left(\mathrm{SpO}_{2}<95 \%\right)$ & 5.181 & 2.242 to 11.905 & $<0.001^{*}$ \\
\hline Rales/crackles & 2.101 & 1.080 to 4.098 & $0.029^{*}$ \\
\hline 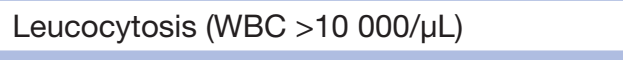 & 3.185 & 1.727 to 5.882 & $<0.001^{*}$ \\
\hline Respiratory acidosis & 7.463 & 3.546 to 15.625 & $<0.001^{*}$ \\
\hline Transaminitis (ALT >3× UNL) & 2.538 & 1.160 to 5.556 & $0.020^{*}$ \\
\hline eGFR (per $1.0 \mathrm{~mL} / \mathrm{min} / 1.73 \mathrm{~m}^{2}$ increment) $\dagger$ & 0.988 & 0.980 to 0.997 & $0.011^{*}$ \\
\hline D-dimer (>500 ng/mL)‡ & - & - & - \\
\hline Ferritin (>336 ng/mL) & 5.376 & 1.789 to 16.129 & $0.003^{*}$ \\
\hline Lactate dehydrogenase (>200 U/L) & 7.634 & 1.739 to 33.333 & $0.007^{*}$ \\
\hline C reactive protein $(>1 \mathrm{mg} / \mathrm{dL}) \ddagger$ & - & - & - \\
\hline Procalcitonin (>0.25 ng/mL) & 2.681 & 1.222 to 5.882 & $0.014^{*}$ \\
\hline Troponin I (>0.03 ng/mL) & 3.390 & 1.751 to 6.536 & $<0.001^{*}$ \\
\hline Opacity/infiltrate on imaging & 2.392 & 1.073 to 5.348 & $0.033^{*}$ \\
\hline Nasal cannula & 2.494 & 1.120 to 5.556 & $0.025^{*}$ \\
\hline High-flow nasal cannula & 5.682 & 2.703 to 11.905 & $<0.001^{*}$ \\
\hline NIPPV & 10.638 & 4.545 to 2.500 & $<0.001^{*}$ \\
\hline Mechanical ventilation & 12.195 & 6.173 to 23.810 & $<0.001^{*}$ \\
\hline ICU admission/transfer & 12.500 & 6.173 to 25.000 & $<0.001^{*}$ \\
\hline ECMO & - & - & - \\
\hline RRT & 23.256 & 6.329 to 83.333 & $<0.001^{*}$ \\
\hline Vasopressor & 17.857 & 8.696 to 37.037 & $<0.001^{*}$ \\
\hline Antibiotics & 20.000 & 2.732 to 142.857 & $0.003^{*}$ \\
\hline Azithromycin & 2.294 & 1.147 to 4.587 & $0.019^{*}$ \\
\hline Hydroxychloroquine & 2.710 & 1.443 to 5.102 & $0.002^{*}$ \\
\hline Steroids & 4.444 & 2.237 to 8.772 & $<0.001^{*}$ \\
\hline Ascorbic acid & 2.639 & 1.370 to 5.076 & $0.004^{*}$ \\
\hline Zinc & 3.650 & 1.898 to 7.042 & $<0.001^{*}$ \\
\hline Tocilizumab & 4.525 & 1.403 to 14.706 & $0.012^{*}$ \\
\hline Convalescent plasma & 4.921 & 2.348 to 10.314 & $<0.001^{*}$ \\
\hline Acute kidney injury & 5.435 & 2.825 to 10.417 & $<0.001^{*}$ \\
\hline ARDS & 23.256 & 11.236 to 50.000 & $<0.001^{*}$ \\
\hline Arrhythmia & 3.610 & 1.645 to 7.937 & $0.001^{*}$ \\
\hline Superimposed bacteraemia & 2.625 & 0.982 to 6.993 & 0.054 \\
\hline
\end{tabular}

*Statistically significant.

†On admission.

$\ddagger$ Analyses cannot be performed as at least one cell is zero.

ALT, alanine transaminase; ARDS, acute respiratory distress syndrome; ECMO, extracorporeal membrane oxygenation; eGFR, estimated glomerular filtration rate; ICU, intensive care unit; NIPPV, non-invasive positive pressure ventilation; RRT, renal replacement therapy; $\mathrm{SpO}_{2}$, oxygen saturation; UNL, upper normal limit; WBC, white blood cell.

predictive of in-hospital mortality. These findings are in line with other cohorts and each factor has been demonstrated as an independent risk factor for mortality in critically ill patients. ${ }^{82-26}$ Although the complications from SARS-CoV-2 infection can be affected by multiple contributing factors, newer evidence has suggested the significance of cytokine storm leading to multiorgan failure. ${ }^{27}$ 
Open access

Table 3 Clinical predictors for overall in-hospital mortality using multivariate binary logistic regression analysis

\begin{tabular}{|c|c|c|c|}
\hline & Statistic & & \\
\hline Characteristics & OR & $95 \% \mathrm{Cl}$ & $P$ value \\
\hline \multicolumn{4}{|l|}{ Model 1} \\
\hline Age (per 1-year increment) & 1.075 & 1.045 to 1.105 & $<0.001^{*}$ \\
\hline Hypertension & 1.264 & 0.572 to 2.793 & 0.562 \\
\hline Chronic kidney disease (CKD) & 1.232 & 0.590 to 2.571 & 0.578 \\
\hline Hypoxia $\left(\mathrm{SpO}_{2}<95 \%\right)$ & 4.630 & 1.934 to 1.111 & $0.001^{*}$ \\
\hline Rales/crackles & 2.016 & 0.955 to 4.255 & 0.066 \\
\hline 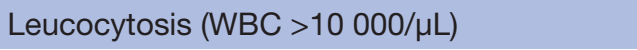 & 2.732 & 1.412 to 5.263 & $0.003^{*}$ \\
\hline Transaminitis (ALT >3× UNL) & 2.137 & 0.890 to 5.128 & 0.089 \\
\hline eGFR (per $1.0 \mathrm{~mL} / \mathrm{min} / 1.73 \mathrm{~m}^{2}$ decrement) $\dagger$ & 1.002 & 0.990 to 1.013 & 0.795 \\
\hline Ferritin (>336 ng/mL) & 4.016 & 1.195 to 13.514 & $0.025^{\star}$ \\
\hline Lactate dehydrogenase (>200 U/L) & 7.752 & 1.639 to 37.037 & $0.010^{*}$ \\
\hline Procalcitonin (>0.25 ng/mL) & 2.404 & 1.011 to 5.714 & $0.047^{*}$ \\
\hline Troponin I (>0.03 ng/mL) & 2.242 & 1.080 to 4.673 & $0.030^{*}$ \\
\hline Opacity/infiltrate on imaging & 3.077 & 1.276 to 7.407 & $0.012^{*}$ \\
\hline Nasal cannula & 1.883 & 0.799 to 4.444 & 0.148 \\
\hline High-flow nasal cannula & 4.608 & 2.053 to 10.309 & $<0.001^{*}$ \\
\hline NIPPV & 7.246 & 2.899 to 18.182 & $<0.001^{*}$ \\
\hline Mechanical ventilation & 13.889 & 6.211 to 31.250 & $<0.001^{*}$ \\
\hline ICU admission/transfer & 13.699 & 6.135 to 30.303 & $<0.001^{*}$ \\
\hline RRT & 21.277 & 5.025 to 90.909 & $<0.001^{*}$ \\
\hline Vasopressor & 22.222 & 9.434 to 52.632 & $<0.001^{*}$ \\
\hline Antibiotics & 17.544 & 2.309 to 125.000 & $0.006^{*}$ \\
\hline ARDS & 23.810 & 10.204 to 55.556 & $<0.001^{*}$ \\
\hline Superimposed bacteraemia & 2.041 & 0.645 to 6.452 & 0.224 \\
\hline \multicolumn{4}{|l|}{ Model 2} \\
\hline Azithromycin & 1.916 & 0.788 to 4.651 & 0.152 \\
\hline Hydroxychloroquine & 1.057 & 0.467 to 2.392 & 0.894 \\
\hline Ascorbic acid & 1.008 & 0.440 to 2.313 & 0.985 \\
\hline Zinc & 1.517 & 0.651 to 3.546 & 0.334 \\
\hline Tocilizumab & 1.499 & 0.381 to 5.917 & 0.562 \\
\hline Convalescent plasma & 1.513 & 0.600 to 3.817 & 0.381 \\
\hline \multicolumn{4}{|l|}{ Model 3} \\
\hline Respiratory acidosis & 3.745 & 1.443 to 9.709 & $0.007^{*}$ \\
\hline Steroids therapy & 1.107 & 0.459 to 2.667 & 0.821 \\
\hline \multicolumn{4}{|l|}{ Model 4} \\
\hline Acute kidney injury & 2.268 & 1.025 to 5.025 & $0.043^{*}$ \\
\hline \multicolumn{4}{|l|}{ Model 5} \\
\hline Arrhythmias as complications & 1.161 & 0.428 to 3.155 & 0.769 \\
\hline
\end{tabular}

Continued 
Table 3 Continued

\begin{tabular}{llll} 
& Statistics & & \\
\hline Characteristics & OR & $95 \% \mathrm{Cl}$ & $\mathbf{P}$ value \\
\hline
\end{tabular}

Model 1 is adjusted for age, sex, ethnicity and obesity.

Model 2 is adjusted for age, sex, ethnicity, obesity, need for oxygen therapy and ICU admission.

Model 3 is adjusted for age, sex, ethnicity, obesity, asthma/COPD, need for oxygen therapy and ICU admission.

Model 4 is adjusted for age, sex, ethnicity, obesity, CKD, need for oxygen therapy and ICU admission.

Model 5 is adjusted for age, sex, ethnicity, obesity, CAD, heart failure, history of arrhythmia/conduction disorder and ICU admission.

*Statistically significant.

ALT, alanine transaminase; ARDS, acute respiratory distress syndrome; CAD, coronary artery disease; COPD, chronic obstructive pulmonary disease; eGFR, estimated glomerular filtration rate; ICU, intensive care unit; NIPPV, non-invasive positive pressure ventilation; RRT, renal replacement therapy; $\mathrm{SpO}_{2}$, oxygen saturation; UNL, upper normal limit; WBC, white blood cell.

Table 4 Demographics and baseline characteristics of critically ill patients $(n=89)$

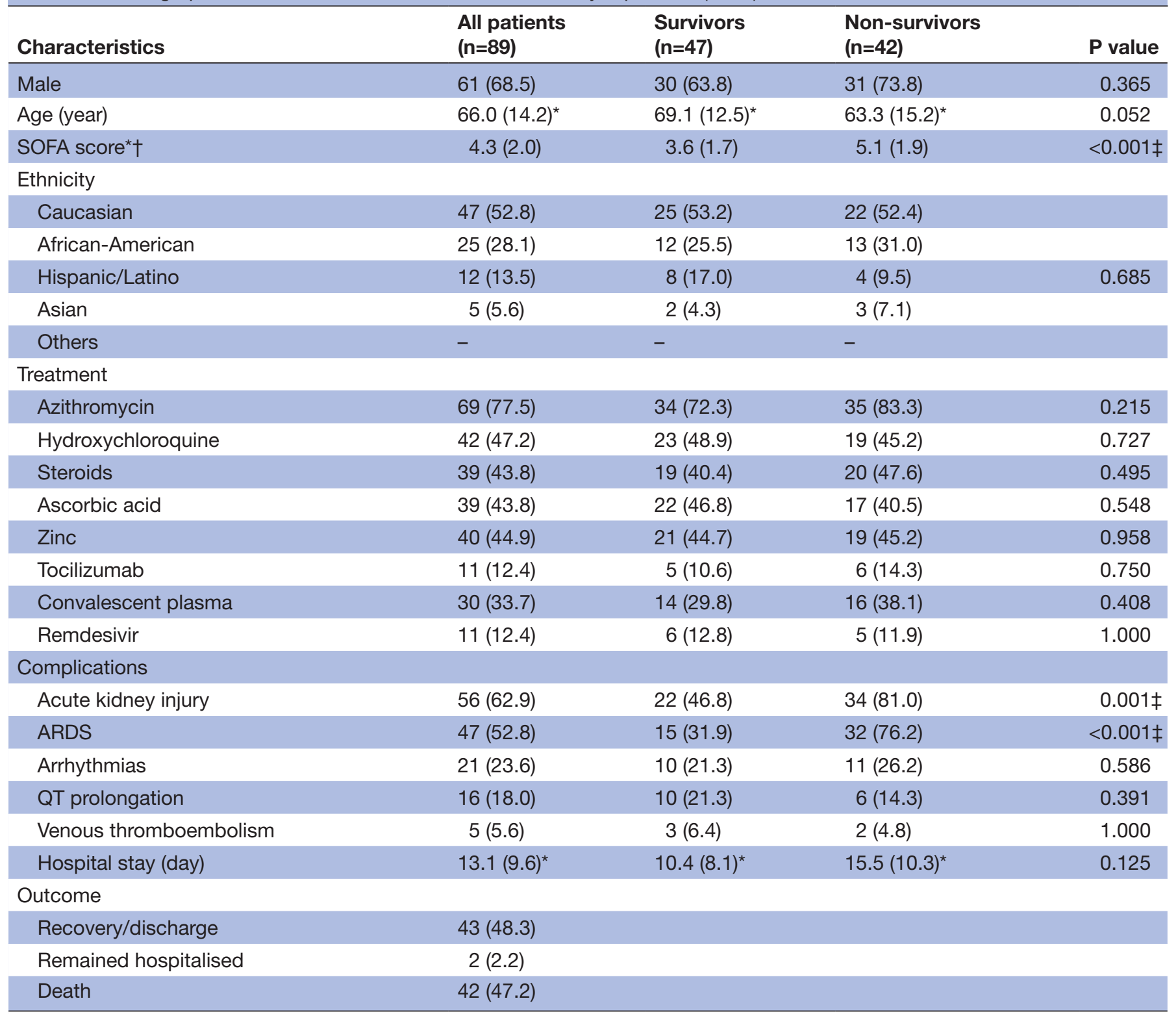

*Mean (SD).

†Collected on the first day of ICU admission.

‡Statistically significant.

.ARDS, acute respiratory distress syndrome; ICU, intensive care unit; SOFA, Sequential Organ Failure Assessment. 
Survival 1 with confidence interval

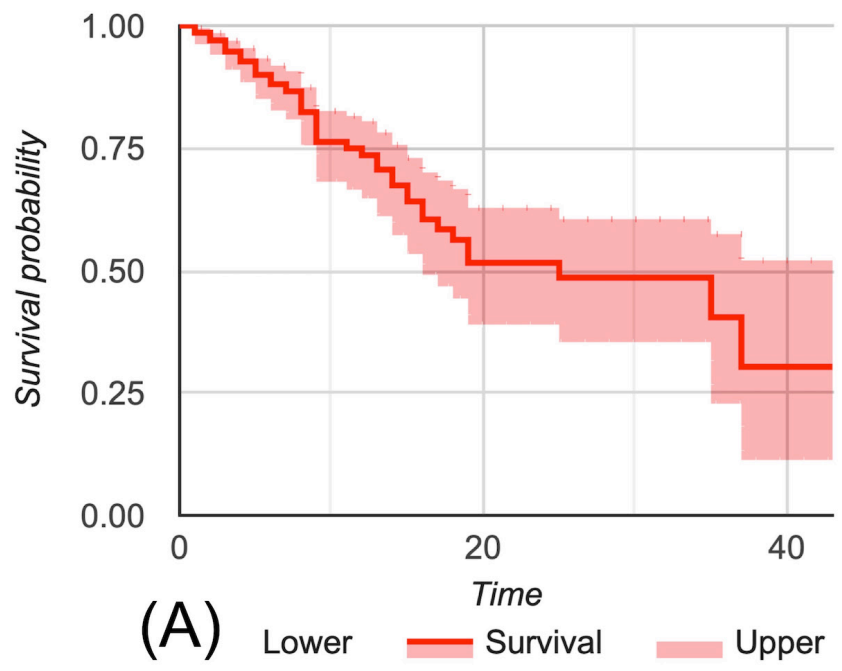

Survival

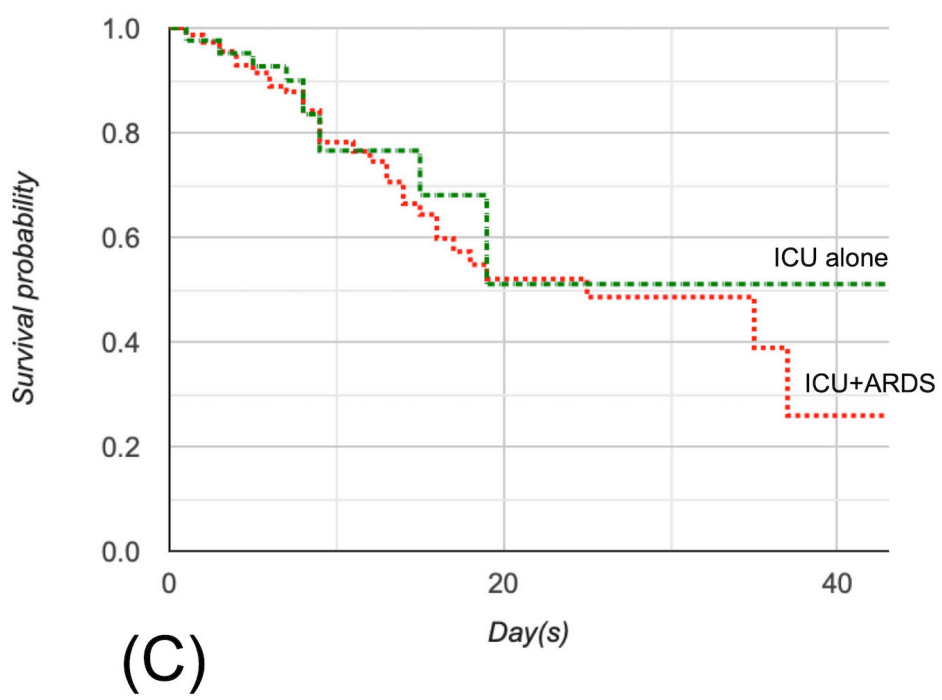

Survival

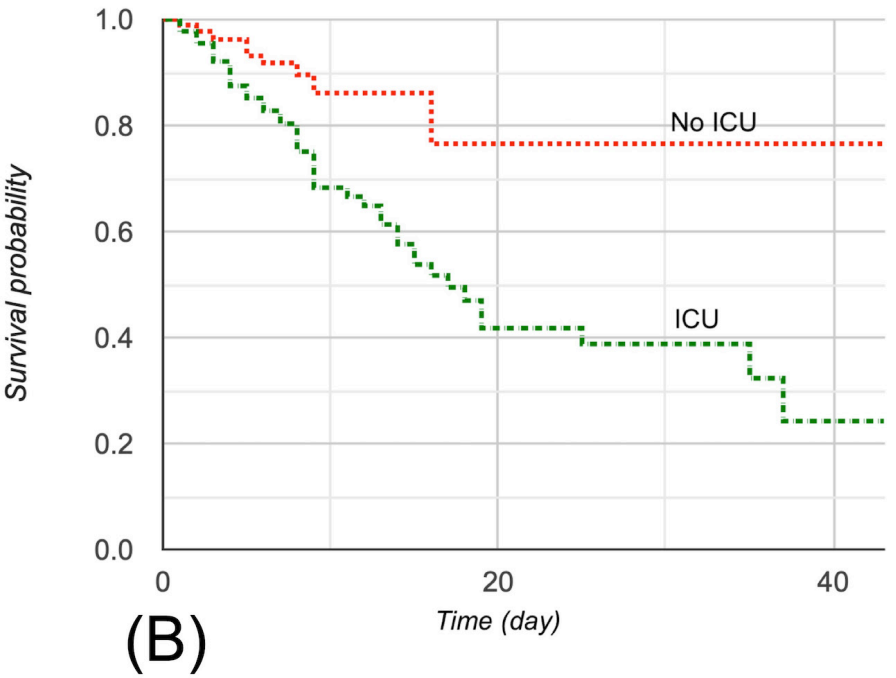

Survival

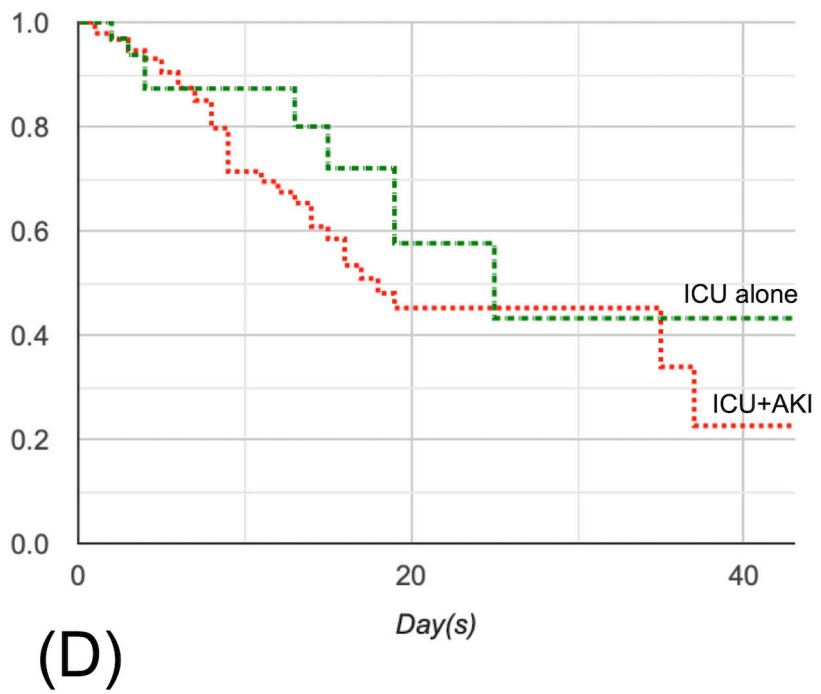

Figure 2 Survival analysis by Kaplan-Meier curves. (A) The cumulative survival declined with increasing length of hospital stay. The median survival time was 25 days with SE of 7.0. (B) ICU patients significantly lower survival probability with mean survival time of 22.3 days (SE 1.8) and 23.0 (SE 1.3) in ICU group versus non-ICU group, respectively ( $p=0.002)$. (C) The cumulative survival between ICU patients with and without acute respiratory distress syndrome (ARDS) ( $p=0.302)$. (D) The cumulative survival between ICU patients with and without acute kidney injury (AKI) $(p=0.504)$. ICU, intensive care unit.

Here, we showed that elevated ferritin, LDH, procalcitonin, leucocytosis, troponin I and possibly D-dimer were associated with increased death. Although the OR for D-dimer cannot be calculated as one cell was zero, we observed that all deceased patients had elevated D-dimer level and the significance of elevated D-dimer toward in-hospital mortality cannot be ignored. Guan et al first demonstrated the importance of elevated inflammatory markers in COVID-19 in Chinese population ${ }^{6}$ which has become a standard monitoring parameter for patients with COVID-19. ${ }^{28}$ Elevated inflammatory markers should prompt physicians to evaluate and monitor the patients for cytokine storms and anticipated clinical deterioration. Elevated procalcitonin and leucocytosis may indicate concomitant bacterial infection, which has been shown to increase morbidity and mortality of viral pneumonia. ${ }^{29}$ Interestingly, our study showed that elevated troponin I level was associated with significantly higher death similar to a recent meta-analysis. ${ }^{30}$ Although the aetiologies of elevated troponin levels were not determined in our cohort, other studies proposed several mechanisms for elevated troponin level in patients with COVID-19. These include myocarditis, cytokine-mediated myocardial injury, microangiopathy of small coronary arteries or silent coronary artery disease. ${ }^{2630}$

The pathophysiology of cytokine storm in SARS-CoV-2 is similar to that of other viruses or bacteria. ${ }^{31}$ Cytokine storm is characterised by the overproduction of 
pro-inflammatory cytokines, such as tumour necrosis factor, interleukin (IL)-6 and IL-1 $\beta$, resulting in an increased vascular hyperpermeability and activation of multiple coagulation pathways. ${ }^{2732}$ In light of SARS-CoV-2induced hypercoagulation, antithrombin III, tissue factor pathway inhibitor and the protein $\mathrm{C}$ system were impaired during active inflammation. ${ }^{33}$ These changes lead to thrombin hyperactivity resulting in the development of microthrombosis, disseminated intravascular coagulation and sequential multiorgan failure. ${ }^{27}$ Moreover, new studies have revealed the spectrum of hyperferritinemic syndromes induced by SARS-CoV-2 but they are beyond the scope of our article. ${ }^{34}$ Such syndromes include macrophage activation syndrome, adult-onset Still's disease and catastrophic antiphospholipid syndrome. ${ }^{34}$

Hydroxychloroquine therapy was associated with a threefold increased risk of QT prolongation but not associated with increased risk of death. The concept of using hydroxychloroquine in patients with COVID-19 derived from an early in vitro study. ${ }^{35}$ The results from small nonrandomised clinical trials also showed promising effects on viral load reduction. ${ }^{36}{ }^{37}$ However, the clinical benefit of hydroxychloroquine was debated by a large observation study. Of 1446 patients, Geleris et al observed that hydroxychloroquine had no effect on the death, length of stay or intubation. ${ }^{38}$ A recent multicentre, randomised, open-label, controlled trial in hospitalised patients with mild-to-moderate COVID-19 found that the use of hydroxychloroquine, alone or with azithromycin, did not improve the clinical outcome at 15 days compared with the standard treatment. ${ }^{39}$ Thus, the recommendation for use of hydroxychloroquine was recalled by the Infectious Diseases Society of America (IDSA) due to small sample size in previous clinical trials and concern for cardiac adverse effects, such as QT prolongation/torsade de pointes. ${ }^{40}$

A meta-analysis of four randomised trials and one retrospective study showed that the administration of intravenous vitamin $\mathrm{C}$ has vasopressor-sparing effects and may reduce the need for mechanical ventilation in critically ill patients while there was no effect on the mortality. ${ }^{41}$ However, given the lack of more supporting evidence, the standard use of ascorbic acid is not yet recommended especially in patients with COVID-19. A new clinical trial investigating the treatment outcome of vitamin $\mathrm{C}$ in severe COVID-19 is underway (NCT04264533).

Although our study also showed that zinc supplementation was not associated with increased mortality in patients with COVID-19, the routine use of zinc supplementation could not be supported due to lack of randomised controlled trials. A Brazilian study revealed that plasma zinc concentration in critically ill patients on admission to the ICU was low and may make these patients more susceptible to oxidative stress. ${ }^{42}$ Another prospective study showed that zinc supplementation in mechanically ventilated patients was related to less ventilator-associated pneumonia. ${ }^{43}$ However, the mean duration of intubation in this study was prolonged (29 days), making it inconclusive if zinc supplementation can prevent pneumonia development in short-term intubation.

Steroid therapy in patients with COVID-19 was not associated with increased mortality. A meta-analysis of 42 randomised controlled trials consisting of 10194 patients has shown that corticosteroids possibly result in a small reduction in mortality and an increased risk of neuromuscular weakness among critically ill patients with sepsis. ${ }^{44}$ However, the theoretical concept for corticosteroid use in COVID-19 was to reduce cytokine storm caused by a reaction to SARS-CoV-2 infection. ${ }^{45}$ In early April 2020, the IDSA recommended against a routine use of corticosteroids in the treatment of COVID-19 due to lack of evidence. ${ }^{40}$ This guideline was updated on 25 June 2020 after the results of the RECOVERY trial were released showing that patients who received dexamethasone were more likely to be discharged from hospital at 28 days compared with non-steroids group. ${ }^{46}$ Thus, currently, the IDSA panel suggests glucocorticoids use in hospitalised patients with severe COVID-19. ${ }^{40}$ Here, our study is in line with the recommendation from the IDSA.

We have observed that remdesivir and tocilizumab were not associated with mortality and there was no significant improvement in hospital length of stay between patients receiving these drugs. However, given the observational, non-randomised design of this study, it is difficult to determine the efficacy of such treatment. Recently, the preliminary report from a phase III randomised controlled trial revealed that remdesivir was superior to placebo in shortening the time to recovery in adults hospitalised with COVID-19. ${ }^{47}$ Several retrospective studies reported that tocilizumab, an IL-6 inhibitor, was shown to reduce the levels of serum inflammatory markers. However, the impact on clinical improvement and mortality remained inconclusive. ${ }^{48-50}$ Although we reported no significant clinical benefits from tocilizumab, the consideration for compassionate use of tocilizumab is not discouraged but rather dependent on the judgement of clinicians based on current evidence. A phase 2 (TOCIVID-19; NCT04317092) and 3 randomised controlled trial (COVACTA; NCT04320615) of tocilizumab is being investigated for the treatment of COVID-19 pneumonia. The preliminary results are expected to be released in late 2020.

Similarly, we found that convalescent plasma was not associated with in-hospital mortality. The safety of convalescent plasma was demonstrated in a single-centre retrospective cohort of 25 patients ${ }^{51}$ and in a preprint, non-peer review report. ${ }^{52}$ However, the efficacy of convalescent plasma remained undetermined due to lack of control group. The IDSA panel has recommended convalescent plasma only in the context of a clinical trial. However, at our institution, convalescent plasma is considered if patients have severe symptoms and have contraindications to remdesivir, such as AKI and hepatic dysfunction. Although we did not observe mortality adverse effect from convalescent plasma, the final recommendations on its efficacy and safety are dependent on the randomised 
controlled trials. To date, at least one randomised controlled trial (NCT04342182) is being investigated to establish the clinical benefits in hospitalised patients with severe COVID-19.

From our ICU cohort, the SOFA score, AKI and ARDS were the only variables that were predictive of mortality among patients admitted to the ICU. Interestingly, all treatment measures had no effect on mortality once patients were critically ill and required ICU. This could imply that these treatment interventions might be beneficial if given prior to clinical decompensation or ICU transfer. However, interpretation is restricted due to small sample size and examining only critically ill patients. Our hypothesis should be substantiated by studies from other institutions with larger sample sizes.

Our study has some limitations. The observational design made the results susceptible to selection bias. Analyses could be underpowered given the small sample size. Moreover, due to restricted availability, not many cases had received compassionate use of tocilizumab, remdesivir and convalescent plasma, which may limit the applicability of our findings. More importantly, the mortality can be affected by confounding factors. We minimise this risk by applying multivariate analysis with models designed to cover all possible confounding factors for each analysed variable. Most of the collected data were cross-sectional, thus, making it difficult to conclude the causality between the two variables. Furthermore, our binary logistic regression analyses may not strictly follow the 1-in-10 rule which may lead to overfitting effect. However, our statistical rationale is supported by newer simulation studies by Vittinghoff and McCulloch ${ }^{53}$ and van Smeden et al. ${ }^{54}$ The length of stay was computed in the Kaplan-Meier analysis to represent the time to death. It is worth noting that the non-survivors had a curtailed length of stay. Moreover, we advised the readers to consider their patient population to determine the applicability of our results.

In conclusion, COVID-19 is a serious condition with a significant in-hospital mortality rate. Multiple risk factors for in-hospital death were identified. Increasing SOFA score, AKI and ARDS are significant risk factors for increased death in critically ill patients.

Contributors KPG, PH and MG collected the data. PH analysed the data. KPG, PH and JDG drafted the manuscript. All authors edited and approved the manuscript for submission.

Funding The authors have not declared a specific grant for this research from any funding agency in the public, commercial or not-for-profit sectors.

Competing interests None declared.

Patient consent for publication Not required.

Ethics approval The protocol of this study has been approved by the UPMC Pinnacle Institutional Review Board and UPMC Pinnacle Ethics Committee (\#20E024).

Provenance and peer review Not commissioned; externally peer reviewed.

Data availability statement Data are available upon reasonable request. Raw data are available upon reasonable request.

Supplemental material This content has been supplied by the author(s). It has not been vetted by BMJ Publishing Group Limited (BMJ) and may not have been peer-reviewed. Any opinions or recommendations discussed are solely those of the author(s) and are not endorsed by BMJ. BMJ disclaims all liability and responsibility arising from any reliance placed on the content. Where the content includes any translated material, BMJ does not warrant the accuracy and reliability of the translations (including but not limited to local regulations, clinical guidelines, terminology, drug names and drug dosages), and is not responsible for any error and/or omissions arising from translation and adaptation or otherwise.

Open access This is an open access article distributed in accordance with the Creative Commons Attribution Non Commercial (CC BY-NC 4.0) license, which permits others to distribute, remix, adapt, build upon this work non-commercially, and license their derivative works on different terms, provided the original work is properly cited, appropriate credit is given, any changes made indicated, and the use is non-commercial. See: http://creativecommons.org/licenses/by-nc/4.0/.

\section{ORCID iD}

Panupong Hansrivijit http://orcid.org/0000-0002-5041-4290

\section{REFERENCES}

1 WHO. Coronavirus disease (COVID-19) pandemic. Available: https:// www.who.int/emergencies/diseases/novel-coronavirus-2019 [Accessed 29 Aug 2020].

2 Department of Health. COVID-19 data for Pennsylvania. Available: https://www.health.pa.gov/topics/disease/coronavirus/Pages/Cases. aspx [Accessed 29 Aug 2020].

3 Arentz M, Yim E, Klaff L, et al. Characteristics and outcomes of 21 critically ill patients with COVID-19 in Washington state. JAMA 2020;323:1612-4.

4 Myers LC, Parodi SM, Escobar GJ, et al. Characteristics of hospitalized adults with COVID-19 in an integrated health care system in California. JAMA 2020;323:2195.

5 Richardson S, Hirsch JS, Narasimhan M, et al. Presenting characteristics, comorbidities, and outcomes among 5700 patients hospitalized with COVID-19 in the new York City area. JAMA 2020;323:2052-9.

6 W-j G, Z-y N, Hu Y. Clinical characteristics of coronavirus disease 2019 in China. New England Journal of Medicine 2020;382:1708-20.

7 RH D, Liang LR, Yang CQ. Predictors of mortality for patients with COVID-19 pneumonia caused by SARS-CoV-2: a prospective cohort study. Eur Respir J 2020;55.

8 Zhou F, Yu T, Du R, et al. Clinical course and risk factors for mortality of adult inpatients with COVID-19 in Wuhan, China: a retrospective cohort study. Lancet 2020;395:1054-62.

9 Gautret P, Lagier J-C, Parola P, et al. Hydroxychloroquine and azithromycin as a treatment of COVID-19: results of an openlabel non-randomized clinical trial. Int J Antimicrob Agents 2020;56:105949.

10 Fowler AA, Truwit JD, Hite RD, et al. Effect of vitamin C infusion on organ failure and biomarkers of inflammation and vascular injury in patients with sepsis and severe acute respiratory failure: the CITRISALI randomized clinical trial. JAMA 2019;322:1261-70.

11 Caly L, Druce JD, Catton MG, et al. The FDA-approved drug ivermectin inhibits the replication of SARS-CoV-2 in vitro. Antiviral Res 2020;178:104787.

12 te Velthuis AJW, van den Worm SHE, Sims AC, et al. Zn(2+) inhibits coronavirus and arterivirus RNA polymerase activity in vitro and zinc ionophores block the replication of these viruses in cell culture. PLoS Pathog 2010;6:e1001176.

13 Ferreira FL, Bota DP, Bross A, et al. Serial evaluation of the SOFA score to predict outcome in critically ill patients. JAMA 2001;286:1754-8.

14 Levey AS, Stevens LA, Schmid CH, et al. A new equation to estimate glomerular filtration rate. Ann Intern Med 2009;150:604-12.

15 Khwaja A. KDIGO clinical practice guidelines for acute kidney injury. Nephron Clin Pract 2012;120:c179-84.

$16 \mathrm{KDIGO}$ clinical practice guideline for the diagnosis, evaluation, prevention, and treatment of chronic kidney Disease-Mineral and bone disorder (CKD-MBD). Kidney Int Suppl 2009;113:S1-130.

17 Ferguson ND, Fan E, Camporota L, et al. The Berlin definition of ARDS: an expanded rationale, Justification, and supplementary material. Intensive Care Med 2012;38:1573-82.

18 Hazra A. Using the confidence interval confidently. J Thorac Dis 2017;9:4124-9.

19 Cheng Y, Luo R, Wang K, et al. Kidney disease is associated with in-hospital death of patients with COVID-19. Kidney Int 2020;97:829-38. 
$20 \mathrm{Li} \mathrm{X}, \mathrm{Xu} \mathrm{S}$, Yu M. Risk factors for severity and mortality in adult COVID-19 inpatients in Wuhan. J Allergy Clin Immunol 2020.

21 Gustot T. Multiple organ failure in sepsis: prognosis and role of systemic inflammatory response. Curr Opin Crit Care 2011;17:153-9.

22 Elseviers MM, Lins RL, Van der Niepen P, et al. Renal replacement therapy is an independent risk factor for mortality in critically ill patients with acute kidney injury. Crit Care 2010;14:R221.

23 Martin C, Viviand X, Leone M, et al. Effect of norepinephrine on the outcome of septic shock. Crit Care Med 2000;28:2758-65.

24 Wang CY, Calfee CS, Paul DW, et al. One-Year mortality and predictors of death among hospital survivors of acute respiratory distress syndrome. Intensive Care Med 2014;40:388-96.

25 Combes A, Costa M-A, Trouillet J-L, et al. Morbidity, mortality, and quality-of-life outcomes of patients requiring $>0$ or $=14$ days of mechanical ventilation. Crit Care Med 2003:31:1373-81.

26 Li J-W, Han T-W, Woodward M, et al. The impact of 2019 novel coronavirus on heart injury: a systematic review and meta-analysis. Prog Cardiovasc Dis 2020;63:518-24.

27 Jose RJ, Manuel A. COVID-19 cytokine storm: the interplay between inflammation and coagulation. Lancet Respir Med 2020;8:e46-7.

28 Annane D, Pastores SM, Rochwerg B, et al. Guidelines for the diagnosis and management of critical illness-related corticosteroid insufficiency (CIRCI) in critically ill patients (Part I): Society of critical care medicine (SCCM) and European Society of intensive care medicine (ESICM) 2017. Crit Care Med 2017;45:2078-88.

29 Morris DE, Cleary DW, Clarke SC. Secondary bacterial infections associated with influenza pandemics. Front Microbiol 2017;8:1041.

30 Vrsalovic M, Vrsalovic Presecki A. Cardiac troponins predict mortality in patients with COVID-19: a meta-analysis of adjusted risk estimates. J Infect 2020;81:e99-100.

31 Tisoncik JR, Korth MJ, Simmons CP, et al. Into the eye of the cytokine storm. Microbiol Mol Biol Rev 2012;76:16-32.

32 Meduri GU, Kohler G, Headley S, et al. Inflammatory cytokines in the BAL of patients with ARDS. persistent elevation over time predicts poor outcome. Chest 1995;108:1303-14.

33 José RJ, Williams AE, Chambers RC. Proteinase-Activated receptors in fibroproliferative lung disease. Thorax 2014;69:190-2.

34 Colafrancesco S, Alessandri C, Conti F, et al. COVID-19 gone bad: a new character in the spectrum of the hyperferritinemic syndrome? Autoimmun Rev 2020;19:102573.

35 Biot C, Daher W, Chavain N, et al. Design and synthesis of hydroxyferroquine derivatives with antimalarial and antiviral activities. $J$ Med Chem 2006;49:2845-9.

36 Gao J, Tian Z, Yang X. Breakthrough: chloroquine phosphate has shown apparent efficacy in treatment of COVID-19 associated pneumonia in clinical studies. Biosci Trends 2020;14:72-3.

37 Gautret P, Lagier J-C, Parola P, et al. Hydroxychloroquine and azithromycin as a treatment of COVID-19: results of an openlabel non-randomized clinical trial. Int $J$ Antimicrob Agents 2020;56:105949.
38 Geleris J, Sun Y, Platt J, et al. Observational study of hydroxychloroquine in hospitalized patients with Covid-19. N Engl J Med 2020;382:2411-8.

39 Cavalcanti AB, Zampieri FG, Rosa RG, et al. Hydroxychloroquine with or without azithromycin in mild-to-moderate Covid-19. N Engl $J$ Med Overseas Ed 2020;383:2041-52.

40 Bhimraj A, Morgan RL, Shumaker AH. Infectious diseases Society of America guidelines on the treatment and management of patients with COVID-19. Clin Infect Dis 2020.

41 Zhang M, Jativa DF. Vitamin C supplementation in the critically ill: a systematic review and meta-analysis. SAGE Open Med 2018;6:205031211880761.

42 Cirino Ruocco MA, Pacheco Cechinatti ED, Barbosa F, et al. Zinc and selenium status in critically ill patients according to severity stratification. Nutrition 2018:45:85-9.

43 Hasanzadeh Kiabi F, Alipour A, Darvishi-Khezri H, et al. Zinc supplementation in adult mechanically ventilated trauma patients is associated with decreased occurrence of ventilator-associated pneumonia: a secondary analysis of a prospective, observational study. Indian J Crit Care Med 2017;21:34-9.

44 Annetta M, Maviglia R, Proietti R, et al. Use of corticosteroids in critically ill septic patients : a review of mechanisms of adrenal insufficiency in sepsis and treatment. Curr Drug Targets 2009;10:887-94.

45 Scaroni C, Armigliato M, Cannavò S. COVID-19 outbreak and steroids administration: are patients treated for Sars-Cov-2 at risk of adrenal insufficiency? J Endocrinol Invest 2020;43:1-2.

46 Dexamethasone in hospitalized patients with Covid-19 - preliminary report. N Engl J Med 2020.

47 Beigel JH, Tomashek KM, Dodd LE, et al. Remdesivir for the treatment of Covid-19 - final report. N Engl J Med 2020;383:1813-26.

48 Luo P, Liu Y, Qiu L, et al. Tocilizumab treatment in COVID-19: a single center experience. J Med Virol 2020;92:814-8.

49 Alattar R, Ibrahim TBH, Shaar SH. Tocilizumab for the treatment of severe coronavirus disease 2019. J Med Virol 2020.

50 Campochiaro C, Della-Torre E, Cavalli G, et al. Efficacy and safety of tocilizumab in severe COVID-19 patients: a single-centre retrospective cohort study. Eur J Intern Med 2020;76:43-9.

51 Salazar E, Perez KK, Ashraf M. Treatment of coronavirus disease 2019 (COVID-19) patients with convalescent plasma. Am J Pathol 2020.

52 Joyner M, Wright RS, Fairweather D, et al. Early safety indicators of COVID-19 convalescent plasma in 5,000 patients. medRxiv 2020. do :10.1101/2020.05.12.20099879. [Epub ahead of print: 14 May 2020].

53 Vittinghoff E, McCulloch CE. Relaxing the rule of ten events per variable in logistic and COX regression. Am J Epidemio 2007:165:710-8.

54 van Smeden M, de Groot JAH, Moons KGM, et al. No rationale for 1 variable per 10 events criterion for binary logistic regression analysis. BMC Med Res Methodol 2016;16:163. 